\title{
P-172
}

\section{Chemical and Biological Investigations of Corypha Taliera Roxb}

\author{
Akhtaruzzaman Chowdury ${ }^{1, *}$, Md. Ashraful Alam ${ }^{1}$, Mohammad S. Rahman ${ }^{2}$, Abul Hassan ${ }^{3}$ and \\ Mohammad A. Rashid ${ }^{2}$
}

${ }^{1}$ Chemistry Research Laboratory, Department of Chemistry, Rajshahi University of Engineering and Technology, Rajshahi, Bangladesh; '2Phytochemical Research Laboratory, Department of Pharmaceutical Chemistry, Faculty of Pharmacy, University of Dhaka, Dhaka-1000, Bangladesh; ${ }^{3}$ Department of Botany, University of Dhaka, Dhaka-1000, Bangladesh; E-mail: akhtarcy@yahoo.com

C. taliera Roxb. (Family- Arecaceae, Bengali name- tali, talier, tara palm) is one of the wonder tree of the palm family. The methanol extract of the fruits of this plant as well as its $n$-hexane, carbon tetrachloride, dichloromethane and aqueous soluble fractions were subjected to screenings for antioxidant, antimicrobial and cytotoxic activities. The methanolic crude extract demonstrated highest antioxidant activity having $\mathrm{IC}_{50} 19.33 \mu \mathrm{g} / \mathrm{ml}$ as compared to $9.5 \mu \mathrm{g} / \mathrm{ml}$ for the standard agents, BHT. The crude methanol extract and its carbon tetrachloride, dichloromethane and aqueous soluble partitionates showed mild to moderate inhibition of microbial growth against some of the tested organisms, while all the extractives exhibited strong cytotoxic property among which the methanol extract revealed the strongest cytotixicity with $\mathrm{LC}_{50} \mathrm{of} 0.43 \mu \mathrm{g} / \mathrm{ml}$. In addition, stigmasterol, $\beta$-sitosterol, $\beta$-amyrin, lupeol and betulinic acid were also isolated from $n$-hexane fraction of the crude methanolic extract. 